\title{
THE IMPLEMENTATION OF SYNCHRONOUS AND ASYNCHRONOUS E- LANGUAGE LEARNING IN EFL SETTING: A CASE STUDY
}

\author{
Rika Riwayatiningsih ${ }^{1}$ \\ University of Nusantara PGRI Kediri, East Java, Indonesia \\ rieka@unpkediri.ac.id ${ }^{1}$ \\ Sulistyani $^{2}$ \\ University of Nusantara PGRI Kediri, East Java, Indonesia \\ sulissulistyani@rocketmail.com²
}

\begin{abstract}
Teaching and learning process since the pandemic time has shifted away from the traditional face to face classroom into online distance learning, and this will be undergo in the post pandemic. This case study aimed to investigate the effectiveness use of the combined modes of synchronous and asynchronous in e- language learning for university students. While both types of that learning approach have its importance in different scenario. The research questions to be answered in the study was how the adoption of synchronous (discussion activity platform) and asynchronous (learning content platform) would be more effective in e- language learning. 55 university participants from the second semester of English Department who joined the online creative writing class in synchronous and asynchronous language learning activity received the survey questionnaire as the sampling of the collected data. The data from the interview was also obtained to get the learners insights regarding the course experiences. The results showed that the applying of the combination approach in online learning has been greatly effective in helping the learners in terms of the community interaction and material engagement. Moreover, the learners' response about the using blended mode of synchronous and asynchronous for their learning is very positive. Some suggestions to enfold the problems over the online learning are also provided.
\end{abstract}

Keywords: Synchronous learning; asynchronous learning; online creative writing

\section{INTRODUCTION}

Many new problems raised by
educators during online distance
learning reshape the education
movement into certain types of
creativity. This can be slow and hard
challenging to provide effective
learning to encourage autonomy and
sustain students motivation at the same
time. The positive perspective on the
current forced dependency on education
technology, however, could intensify
some changes that have already begun.
It may affect the educators to think
harder about current models of

education, to learn more quickly which of the technical uses are successful and which are not (Thomas \& Rogers, 2020). And this becomes the fact that the conditions of education must encounter.

The use of digital communication technology and networked online applications, along with features, demands, and challenges of teachers and students, have changed and shaped the global learning environments of the twenty- first century (Mcloughlin \& Lee, 2010). Educators are struggling to 
find options to deal with this challenging situations. This is a situation that accosiated with accesibility, affordability, flexibility and learning pedagogy with e- learning (Dhawan, 2020). Indeed managing learners at a distance using digital tools requires that instructors develop alternative teaching strategies from those used in traditional classroom.

Giving some considerations to the improvement of students creative writing in online learning situation drew severe attentions to the kinds of creative collaboration afforded through digital platform. Integrating the writing process through the use of computer platform considered will be more amusing and entertaining for students (Kaleci \& Korkmaz, 2016). That is because another students can improve the current product, and even can make changes on it. Innovative and creative thinking of the students is promoted through this path. With this, students who lack the courage to use their writing skill effectively overcome with this obstacle with writable method, in so this students overcome their lack of trust and grow as authors (Carolan \& Kyppö, 2015). As such, the students will get the chance to control themselves to be responsible with the process as they become more confident (Beck, 2004).

Relating to the factors that effect students' performance in online creative writing, the effective use of the technology platform should be taken as the attentation to support the acquisition in writing ability. Relationship between the use of sequencing synchronous and asynchronous tools may influence the effectiveness learning (Ene \& Upton, 2018). The effect of synchronous as well as asynchronous use of technology indicates that, as a negotiation- based and dialogic process, will support the writing acquisition. Therefore, this study attemps to investigate how the use of the blended modes of synchronous and asynchronous tools affect the students' learning engagement and proficient in their online creative writing. Just as (Sudewi, n.d.) stated that blended online learning modes made students to be more motivate in their active learning and challenge either in their learning experience and learning style.

\section{LITERATURE REVIEW}

Globalization and developing knowledge set new standards for all aspects of social life, including higher eduction. In the modern digital age educational climate, online learning has become an essential instrument that enables student-centered learning and educational practice, providing new more versatile new learning methods (Kumar Goyal, Malhotra Assistant Professor, \& Goyal Associate Professor, 2013). Various technologies are applied to the environment in order to make learning easier and in a form of collaboration. The online learning environment is supported with technology platform both synchronous and asynchronous.

\subsection{Synchronous Learning}

Synchronous learning is the kind of learning that happens in real time. This means that students and the instructor interact in a specific virtual place, through a specific online medium, at a specific time. In other words, it's not exactly anywhere, anyhow, anytime. Methods of synchronous online learning include video conferencing, teleconferencing, live chatting, and livestreaming lectures. Synchronous learning has a number major benefits such as direct input, greater encouragement and the responsibility to participate and be present (Redmond, 
Parkinson, Mullally, \& Dolan, 2007). Further, in carrying out teamwork for courses involving community interactions, synchronous online conferences can be quite useful and even advantageous for students when they resolve their space constraints, time limits, and scope (Tabak \& Rampal, 2014). Moreover (Hyder et al., 2007) define the key advantages to using synchronous online learning include:

Connecting dispersed learners: Synchronous approaches are particularly useful for organizations that have geographically scattered learning populations.

Real-time interaction and collaboration: Synchronous tools let the users communicate with others which allows a spontaneous and flowing learning session in real time. Responses immediate questions may be answered, and clarification may be given directly. Synchronous tools also lend themselves well to structured collaborative assignments. The social dimension of synchronous tools creates a learning synergy.

Sense of immediacy and co-presence: Synchronous devices are suitable for late- breaking transmission and time sensitive news. Since the human presence is so "front and center" when using these technologies, the resulting learner experience that is generated allays anxieties about the mechanical or depersonalized essence of technologyenabled learning.

Fostering a learning community: Apprentices benefit from exchanging thoughts and experiences with their peers. A major benefit of synchronous online learning platforms is the creation of a sense of link between learners and group. Long-term impacts may include strengthened teamwork and organizational skills, better retention of workers, higher morale, and creation of group identity. In particular, adult learners respond favorably to peer support and opportunities to connect with their co-workers. Polling tools and other synchronous features may be used to create a sense of unity, or to establish interest within a workforce for the difersity of ideas.

Balancing learning dynamics: Synchronous e-Learning will reduce the imbalances and create a learning environment that is more equitable. The power dinamic of face- to- face learning environment can be avoided, where extroverts can dominate, and where gender and other personal characteristics can affect group activities. Effectively used, synchronous learning tools can resolve some of those obstacles and level the field (though technical literacy can create imbalances among learners if it is not properly accounted for). Using anonymous feedback tools (such as polls and surveys) can improve online participants' comfort level by reducing the concerns that adult learners frequently have about reacting inappropriately in front of peers. On the other hand, using tools that do recognize the originator (such as Text Chat) can allow participants to shine before their collegues and build a healthy competition. More generally, the variety of tools and communication choices available in synchronous eLearning (text Chat, audio, polling, etc.) provides numerous options for connecting with diverse learners with different learning styles.

Unique functionality: Many synchronous e-Learning tools include features and functionality that offer unparalleled opportunities for fast and effective learning. Whiteboarding and markup tools can permit class exercises that can be easily saved and recalled. 
Application sharing allows for rapid and easy group work.

2.2. Asynchronous Learning

Asynchronous learning is general term used to describe forms of education, instruction, and learning that do not occur in the same place or at the same time. (Swan, 2002) identified three main factors that contribute significantly to the success of online courses on; a clear and consistent course structure, an instructor who interacts frequently and constructively with students, and a valued and dinamic discussion. However that discussion strategies requiring learners to take a perspective in an authentic scenario facilitate cognitive presence, and thus critical thinking and higher level of learning (Darabi, Arrastia, Nelson, Cornille, \& Liang, 2011). Accordingly, (Swan, n.d.) suggeted that three factors are associated with the student perceptions of satisfaction and learning in online courses- interaction with course content, interaction with course instructors, and interaction among course participants. Moreover, (Garrison, n.d.) pointed out that to understand learning effectiveness for asynchronous online learning is to first appreciate what is unique about this medium. That is, it is how to combine and integrate the reflective and collaborative possibilities that model the insperable private and public worlds of the learner that will make the learning experience effective for all concerned.

\subsection{Online Creative Writing}

To create an experience that will be mutually beneficial to the online writing process needs collaborativelly planned of the overall online writing process. (Saine \& West, 2017) find that virtual writing experience are influenced by nine specific experiences. These experiences include (a) giving feedback, (b) working with students, (c) becoming a tech- savvy teacher, (d) gaining insight into student writing, (e) recalling previous experiences, (f) gaining knowledge of online resources for teaching writing, (g) appreciating teacher support, (h) becoming conscious of their own emotions, and (i) gaining confidence to respond to students. The best advantage of technology reveals to better understand the cognitive, social, and affective influences teacher responses exert on students as they write (Kim, 2004).

Furthermore, (Beck, 2004) proposes a five- stage model in designing online teaching as access and motivation, online socialisation, information exchange, knowledge construction, and development. It is up to the teacher to design a cooperative learning environment that motivates the students and facilitates their learning efforts (Carolan \& Kyppö, 2015). The online atmosphere created the ability for students to connect with a peer in an authentic context where langugae has been obtained, the target language of interlocutors are more likely than in school when the interactive nature of technology mediation benefits the interactions of foreign language learning (Tolosa, East, \& Villers, 2013). Although face- to- face interaction in language learning is still essential, technologies have the potential to enhance the process of language acquisition and encourage the formation of electronic communities of learning.

The exertion of writing practice into online network is also beneficial in that it improves english proficiency, thinking ability, and communication skills by creating a sense of community, enhancing confident and restoring some participant's interest in writing. This may happen because there are some exposure that make the authors take the responsible of their writing product as 
there is a relationship between writer and reader in that online platform (Xiang, 2017). In addition (Nair, Tay, \& Koh, 2013) stated that with the advantage of platform in online writing, it presents the useful insights and considerartions on the technology to circumvent the possible challenges of using online writing tools.

\section{RESEARCH METHOD}

The researchers used the methods of triangulate data concerning to the objective of the research. The adoption of the methods used to investigate how the synchronous modes in zoom platform followed by the whatsapp group chatroom blended with asyncronous modes in edmodo platform ensued with Wattpad as the writing tool. The data collected in this qualitative study was the observation along the a/synchronous setting, a survey questionnaire concerning with the blend platform used and an informal interview to gather the opinions from the students about their experiences culvivate the technology platform .

\section{Population and sampling}

In relation to the two virtual learners in synchronous and asynchronous modes, the researcher selected the second semester students who took writing online class. 50 elearners who have adhered in several activities through synchronous zoom platform and WhatsApp chatroom along with asynchronous edmodo and Wattpad platform appointed as the sample size for the study. The class was acquiring the creative writing study in a/synchrounously during administering of the distance online learning.

\section{Data collection tools}

The researcher presented the instrument which is appropriate to determine the students preference of the blended use of the two modes in synchronous and asynchronous platform for their online learning. The instrument has been developed to question among the e-learners about their online experiences. The questionnaire consisted of 20 questions which are correlated to e- learning classroom, tools, preferred e- facilities, attending point, lecturing, and its affiliated modes that are synchronous and asynchronous learning environment. Questions were asked to the virtual students purposefully and indirectly about the preference types, available methods on instruments which were provided and commonly applied by students in online environment. The main purpose of the questionnaire was to assess the elearners perception about the blended used of syncronous and asynchronous modes in their online learning. The questionnaire included in the survey were both open and close-ended questions to gain maximum insight about students' experiences in a/synchronous circumstances. The informal interview collected via zoom room during the online writing course administered.

The synchronous and asyncronous platform utilization

Students participated once a week in the writing course where they would eventually attach in several activities. The first activity was preceded by the displaying the subject matter presented in edmodo platform. It offered the students to get the information and new material easily. At this time, the students tackled as the self learners to grasp over the new material. In addition, this activity could bring students to be ready and prepare with the topic. The edmodo platform offers a communication, collaboration, and coaching between teacher and students. The instructor shared the course contents, distributed quizzes, 
assignments, and at the same time managed communication with students.

The second activity followed by an oral discussion board across the zoom platform to engage in conversation between students and the instructor about the material given in edmodo previously. This helped both the students and the instructor communicating the intention and the problems over the material. The information and explanation provided comprehensibly by the instructor at this session. This phase was used to perceive and confirm about the contents which students have obtained from the earliest paltform, edmodo. Here, the extended explanation were scribbled interactively.

The third phase was continued into whatsapp group chatroom where it motivated the lower students to talk more freely around the difficulty. This medium helped to creep in the interactions in collaborative learning. And The last phase was the usage of the Wattpad application for students as a media to publish their writing product. To support students proficiency in their writing skills, the instructor collaborated the wattpad platform to form a community between writers and readers.

\section{RESULT AND DISCUSSION}

The major focus of this study was to examine how the blended synchronous and asynchronous modes can assist the students in online creative writing. Based on the clasification of the data collection, the researcher analysed the research questions in two parts. Following is the description of the data compilation.

4.1. Perception about a/ synchronous elearning

The open and close-ended questions about the students awareness on a/ synchronous modes showed that all participants were not aware of the term of a/ synchronous e- learning. In spite of the fact that they have participated their online courses using zoom and some other platform during their distance learning, the terms a/ synchronous were not informed steadily. Nevertheles, they considered that this kind of learning was fit with the current condition in which technology become an important role in the daily life. Also they found its interesting and easy to access the content. While the question seeking participant's opinion whether elangauge learning could be better learnt a/synchronously or not, the whole participants were positive and in favor of the language learning modes.

In relation with the technology issue,students viewed that technology support and improve their productivity in learning towards the use of simple technology. The involvement into the classroom environment because of the simplicity use of the tools. Therefore, they were aware with the digital learning tools which offered experiences and learning material. The whole of students believed that by connecting teaching with technology helped them improve the personalize learning and also increased students engagement in accelerating learning. (Stroud, 2013) asserted that if technology is to be used approriately, it will highly engage students in their classwork. Effective classroom learning Through encouragement of use with available technology,

4.2. E- writing classroom in a

blended a/ synchronous modes

This section was seeking the participants' opinion whether the writing skill could be better learnt a/ synchronously or not throughout the 
online circumstances. Considering the distance learning situation, the participants were preferred subsequently with the blended modes for their academic performance. The preferrence of the applying blended modes of a/ synchronous platform appeared from the positive attitude from their learning style. The blend mode of synchronous e- learning through zoom and whatsapp group platform facilitated students to the interactions to communicating the problems with the work. The suplementary board gave a positive effect in the online learning in order students participated in new ways (Oztok, Zingaro, Brett, \& Hewitt, 2013). In addition, the synchronous online environment helped to develop deeper understanding about the content presented in asynchronous learning, and this would encompass deep learning (Perveen, 2016). While the asynchronous mode served in edmodo platform considered to deliver the learning materials and it also functioned to build self- learning among students. The media provided cognitive activities and it revealed with taskbased supported with evaluation process (Riwayatiningsih, n.d.).

Students shared that being part of an online blended synchronous and asynchronous course gave them the opportunity to experience an eminent involvement in a flexible learning environment where they had no time to be an inactive participant. This can be seen from students' respons that through the blended format and seeing how the asynchronous activities built towards the synchronous meetings, they were able to continue participating in the asynchronous activities. This preference equal with (Onlinecourses \& Yamagata-Lynch, n.d.) that through the synchronous communications, students were able to engage in spontaneous discussions while through the asynchronous communications they were able to take the time to prepare and reflect a response for discussion topics that were designed for any given week. Looking at the results of interview accordance with students'perception of wattpad indicated that they found that the tools helped them in developing various vocabularies in composing in several genres in creative writing. On the other point, they also presented that wattpad envirornments gives some advantages in terms of time saving and quick feedback. They mentioned the use of technology specifically wattpad, can solve some problems such as motivation and do the task without pressure.

Moreover, the description reagarding with the students interview on their experiences with online distance learning resulted into some points (a) online assessments are supposed to be given entirely based on subjective assessment of efforts and proficinecy. To prevent lag in academic performance, teachers have to ensure that students are assessed in their online classes similar to their face- to- face class. (b) although the convenience of working from home seems like a blissful ideas, teachers are responsible for facilitating online discussion boards when promoting participation and collaboration. (c) teachers can set aside time beforehand for live question and answer by the time scheduled live lecture in which students who attend can give immediate reaction towards the content.

\section{CONCLUSION}

While this study is a single study investigating whether the application of blended modes in synchronous and asynchonous online platform preserve the students' engagement in their online 
creative writing, the results indicate that introducing combination discussion board and content materials board can have positive effects. This finding is in line with (Methaneethorn, n.d.) that the students' attitudes were positive with the writing tools and they felt satisfied with e learning and it suitable with the current condition. The strong correlation between virtual classroom using zoom which structured learning experiences within flexible online learning spaces and asynchronous exercises suggest that there are many engaged students who are taking advantage of the affordances of the combined platform in order to participate in a new ways. This findings support the result from (Ahmad \& Bokhari, 2011) that blended e learning system provides multi platform tools by which traditional instructors can archieve their learning materials and students can do their personal learning over the internet. It is important to add that the lack of synchronous tools in the online course, indeed will be advocated with asynchronous tools.

\section{SUGGESTION}

There are some suggestions that can be given to teachers who have problems and difficulties in online language classroom. First, it will better and more effective when techers use any kind of technology in the teaching and learning process. Since technology has become a medium of distance learning during and after the pandemic time, the use of blended modes of the technology platform is considered the better way in order to hold the cognitive competence and the engagement. Second, use any kind of technology that is easy to operate and understand by students. The use of technology that is familiar and simple make students more excited and active. Besides the use of media in the teaching and learning process, the techniques that teachers use are also essential. These factors will affect the delivery of materials to the students.

\section{REFERENCES}

Ahmad, I., \& Bokhari, M. U. (2011). Distance Education: From Asynchronous to Synchronous ELearning (Vol. 1).

Beck, H. (2004). Teaching creative writing online. New Writing, 1(1), 23-36.

https://doi.org/10.1080/147907204 08668189

Carolan, F., \& Kyppö, A. (2015). Teaching process writing in an online environment. In Voices of pedagogical development - Expanding, enhancing and exploring higher education language learning (pp. 13-30). https://doi.org/10.14705/rpnet.201 5.000285

Darabi, A., Arrastia, M. C., Nelson, D. W., Cornille, T., \& Liang, X. (2011). Cognitive presence in asynchronous online learning: A comparison of four discussion strategies. Journal of Computer Assisted Learning, 27(3), 216-227. https://doi.org/10.1111/j.13652729.2010.00392.x

Dhawan, S. (2020). Online Learning: A Panacea in the Time of COVID-19 Crisis. Journal of Educational Technology Systems, 49(1), 5-22. https://doi.org/10.1177/004723952 0934018

Ene, E., \& Upton, T. A. (2018). Synchronous and asynchronous teacher electronic feedback and learner uptake in ESL composition. 
Journal of Second Language Writing, 41, 1-13. https://doi.org/10.1016/j.jslw.2018. 05.005

Garrison, D. R. (n.d.). Cognitive Presence For Effective Asynchronous Online Learning: The Role Of Reflective Inquiry, Self-Direction And Metacognition.

Hyder, K., Kwinn, A., Miazga, R., Murray, M., Holcombe, D., Clark, R., ... Rossett, A. (2007). Synchronous e-Learning The eLearning Guild's Handbook on The eLearning Guild ${ }^{T M}$ Advisory Board The eLearning Guild's Handbook on Synchronous $e$ Learning $i$. Retrieved from www.elearningguild.com

Kaleci, D., \& Korkmaz, Ö. (2016). Web based interactive online creating your story portal. Pegem Ĕgitim ve Ö̆rretim Dergisi, 6(2), 169-186. https://doi.org/10.14527/pegegog.2 016.010

Kim, L. (2004). Online Technologies for Teaching Writing: Students React to Teacher Response in Voice and Written Modalities (Vol. 38).

Kumar Goyal, A., Malhotra Assistant Professor, S., \& Goyal Associate Professor, A. K. (2013). Role of Online Education in Modern Education System Testing of Efficient Market Hypothesis: A Study on Stock Market Reaction to Dividend Announcements View project ROLE OF ONLINE EDUCATION IN MODERN EDUCATION SYSTEM. In $A n$ International Journal of Research in Management \& IT. Retrieved from

https://www.researchgate.net/publi cation/338829743

Mcloughlin, C., \& Lee, M. J. W. (2010). Personalised and self regulated learning in the Web 2.0 era: International exemplars of innovative pedagogy using social software. In Australasian Journal of Educational Technology (Vol. 26).

Methaneethorn, J. (n.d.). The Development of Blended Synchronous and Asynchronous eLearning for the Subject of Computer Game in Education. In International Journal of the Computer, the Internet and Management (Vol. 21).

Nair, S. S., Tay, L. Y., \& Koh, J. H. L. (2013). Students' motivation and teachers' teaching practices towards the use of blogs for writing of online journals. Educational Media International, 50(2), 108-119. https://doi.org/10.1080/09523987.2 013.795351

Onlinecourses, S., \& Yamagata-Lynch, L. C. (n.d.). Blending Online Asynchronous and Synchronous Learning.

Oztok, M., Zingaro, D., Brett, C., \& Hewitt, J. (2013). Exploring asynchronous and synchronous tool use in online courses. Computers and Education, 60(1), 87-94.

https://doi.org/10.1016/j.compedu. 2012.08.007

Perveen, A. (2016). Synchronous and Asynchronous E-Language 
Learning: A Case Study of Virtual University of Pakistan. Open Praxis, $8(1)$. https://doi.org/10.5944/openpraxis. 8.1.212

Redmond, J. A., Parkinson, A., Mullally, A., \& Dolan, D. (2007). Synchronous e-learning: Three perspectives. Innovations in $E$ Learning, Instruction Technology, Assessment, and Engineering Education, 175-180. https://doi.org/10.1007/978-14020-6262-9_31

Riwayatiningsih, R. (n.d.). Rika Riwayatiningsih: A Study on Students' Learning Interest in Blended Learning Method Through Edmodo to the Students of English Department at Nusantara PGRI Kediri A Study on Students' Learning Interest in Blended Learning Method Through Edmodo to the Students of English Department at Nusantara PGRI Kediri University. Retrieved from www.edmodo.com.

Saine, P., \& West, J. A. (2017). Content Area Teacher Candidates' SelfEfficacy Beliefs of Teaching Writing Online. Journal of Digital Learning in Teacher Education, 33(2), 69-77. https://doi.org/10.1080/21532974.2 017.1280433

Stroud, R. (2013). Utilizing Existing Classroom Technology to Enhance Student Engagement Nishinomiya, Japan. In Kwansei Gakuin University Humanities Review (Vol. 18).

Sudewi, P. W. (N.D.). Learning
Experiences Using Blended Learning On Efl Learners At Sulawesi Barat University.

Swan, K. (n.d.). Virtual interaction: Design factors affecting student satisfaction and perce.

Swan, K. (2002). Building Learning Communities in Online Courses: the importance of interaction. Communication \& Information, 2(1).

https://doi.org/10.1080/146363102 200000501

Tabak, F., \& Rampal, R. (2014). Synchronous e-learning: Reflections and design considerations. In International Journal of Education and Development using Information and Communication Technology (IJEDICT) (Vol. 10).

Thomas, M. S. C., \& Rogers, C. (2020). Education, the science of learning, and the COVID-19 crisis. Prospects. https://doi.org/10.1007/s11125020-09468-z

Tolosa, C., East, M., \& Villers, H. (2013). A publication of the International Association for Language Learning Technology (Vol. 43).

Xiang, Z. (2017). Advanced Chinese EFL Learners' Experiences and Perceptions of OGSW - An Online Collaborative Creative Writing Project. Proceedings - 5th International Conference on Educational Innovation through Technology, EITT 2016, 187-192. https://doi.org/10.1109/EITT.2016. 44 